distance from others. On the other hand, he held advanced standards of rigour and elegance. More than any other scholar, Professor Cohen himself has taught us to appreciate Newton's immense care in his presentation as he continually revised everything he wrote to express his exact meaning. In the present book, he now asks us to receive these same writings as autobiographical accounts of the process by which Newton arrived at his conclusions. Paradoxically, this leads Cohen wholly to reject the validity of genuine autobiographical statements which appear in some of Newton's manuscripts. No doubt the statements were usually self-serving. At best they must be handled with caution, and perhaps some or even all of them need in the end to be dismissed entirely. Surely, however, it is not the published form of non-autobiographical works that can determine what to accept and what to reject.

Cohen's approach leads him to insist that, because Newton expressed reservations, he never seriously entertained the existence of particulate forces in matter and that, because he stated in the Principia that gravitational attraction may be performed by impulse, he always believed that the final explanation of gravity would involve a material aether. Cohen's own theory of the Newtonian style applied to the context of justification puts this material in quite a different light. With a remarkably cold eye, Newton distinguished demonstration from speculation, even when the speculation contained some of his most cherished convictions. He chose not to mix mere belief, no matter how deeply held, with what he took to be demonstrations. When we approach his work from this angle, the very concept of a Newtonian style leads us to an account of the development of Newtonian science that is quite different from the one Professor Cohen presents. In my opinion, it is a more convincing account. We see a Newton who was the boldest speculator of the century, a man who was able to break out of the confines of received natural philosophy and to put questions no one else could formulate. The Newtonian style, the separation of speculative explanatory hypotheses from mathematically demonstrated regularities in nature, controlled the speculation by proposing what he could not demonstrate under titles such as "Queries".

Thus I like the notion of a Newtonian style; it gives definite form to important characteristics of Newton that have hitherto not been clearly perceived and articulated. At the same time, I remain to be convinced that the Newtonian style is a useful instrument in the elucidation of Newton's own scientific development.

Richard S. Westfall is Professor of History and Philosophy of Science at Indiana University, Bloomington, and author of Never at Rest: A Biography of Isaac Newton (Cambridge University Press, 1981 ).

\title{
Minerals through the microscope
}

\section{R.A. Howie}

Optical Mineralogy: The Nonopaque Minerals. By Wm Revell Phillips and Dana T. Griffen. Pp.677. ISBN 0-7167-1129-X. (W.H. Freeman: 1981.) £24.60, \$39.95.

Al.THOUGH this book was originally intended to be the companion volume to Mineral Optics: Principles and Techniques (1972), to supply the necessary tables of properties and mineral descriptions, it developed into a more comprehensive work. There are two quite distinct parts: Part I contains detailed descriptions of most varieties of the common rockforming mineral groups, while Part II presents an "abbreviated summary" (pp.399-665) of the optical properties of "all" non-opaque mineral species (including some first described as recently as 1979). The optical descriptions are illustrated with orientation sketches and determinative graphs of optical properties against composition, though unfortunately refractive indices are given as $n_{\alpha}$, $n_{\varepsilon}$ etc. rather than as $\alpha, \varepsilon$ as recommended by the International Mineralogical Association. For a small proportion of the minerals there are diagrams of the crystal structure, but although the compositional ranges are discussed there are no phase diagrams at all (even for the $\mathrm{Al}_{2} \mathrm{SiO}_{5}$ system of the plagioclase series). Notes on zoning, alteration, distinguishing features and occurrence are included, together with a few selected references.

In addition to summaries of the optical and physical constants of the non-opaque minerals, Part II also gives the typical habit, colour (in thin-section and in hand specimen), alteration and occurrence, together with remarks (solubility, group, polymorph etc.) and one reference. The authors state in their preface that it is hoped that this volume will be accepted as the logical successor to A.N. Winchell's

Science and the President. Pergamon Press have recently issued in paperback Science Advice to the President, a volume tackling many of the same questions raised by Harvey Brooks in his review of Science at the White House by E.J. Burger (Nature 290, 634). The book is a collection of 23 essays by all but one of the past Science Advisers and by other wellqualified individuals, edited by William $\mathrm{T}$. Golden. Prices are hbk £25, \$50; pbk £5, $\$ 9.95$.

British Anthozoa. In his review of British Anthozoa (Nature 291, 520) Sir Maurice Yonge regretted the absence of colour illustrations from the book. R.L. Manuel has compiled another guide to anthozoans which contains colour photographs of all but three of the British species. The book was published last year by the Underwater Conservation Society and is available from UCS Sales, 148 College St, Long Eaton, Nottingham NG10 $4 \mathrm{GX}$, price $£ 16$.
Elements of Optical Mineralogy, II: Descriptions of Minerals (Wiley, 1951) and Larsen and Berman's The Microscopic Determination of the Nonopaque Minerals (US Geological Survey, 1934), both long out of date and out of print. Comparison might also be made with Kostov's Mineralogy (author's translation edited by P.G. Embrey and J. Phemister), published by Oliver \& Boyd in 1968. Certainly, Part II of the present work will prove invaluable. With the rapid discovery of new minerals (currently at the rate of around 80 each year) no single work can ever contain all critical data on all non-opaque minerals, but mineralogists will be in debt to Phillips and Griffen for some years.

In Part I, the detailed descriptions of the commoner rock-forming minerals are wellpresented, yet surely are not quite detailed enough. Comparison is inevitably to be made with Battey's Mineralogy for Students (Oliver \& Boyd, 1972) or Deer, Howie and Zussman's Introduction to the Rock-Forming Minerals (Longmans, Green, 1966). Admittedly the present work is concerned with opticalmineralogy, but it does include sections on the occurrence of the various minerals and these are not always sufficient for a petrologically inclined mineralogist, e.g. for the garnet group. Nor are the references particularly up-to-date - the most recent augite reference is to a 1970 paper, and for biotite, 1966, though perhaps this is merely a reflection of the increasing use of X-ray and electron microprobe techniques in preference to those of optical mineralogy. The amphibole sections take no account of the IMA rulings (1978) for the nomenclature of this group. Nevertheless this descriptive part of the book is well-produced and attractively presented with numerous clear diagrams and quite a few microphotographed pairs (taken with plain-polarized light and with crossed polars). It must be said, however, that after the colour photographs in MacKenzie and Guilford's recent Atlas of Rock-forming Minerals in Thin Section (Longman, 1980), these black-andwhite photographs seem uninspiring.

Perhaps the biggest surprise about this book is the juxtaposition of the two parts which would seem to cater for rather different levels of readership. The listing of properties of all known non-opaque minerals in Part II will appeal to final-year honours students and particularly to research workers at all levels, whereas the mineral descriptions in Part I would, in my opinion, be insufficient for a final year honours course in geology. It is, however, remarkably good value at under $£ 20$; all libraries catering for the earth sciences should have it.

R.A. Howie is Professor of Mineralogy at King's College, University of London. 